\title{
RISK AND PREVENTING OF COVID-19 IN A COMMERCIAL AIRCRAFT CABIN: AN OVERVIEW
}

\author{
Chanfiou Ahmed Mboreha \\ Aeronautical Engineering Department, \\ Nanjing University of Aeronautics and Astronautics, \\ Jiangsu, Nanjing, China \\ Chaharzad Said Abdallah \\ Second Hospital of Jilin University, \\ Jilin, Changchun, China \\ Gaurav Kumar \\ Department of Mechanical Engineering, \\ Delhi Technological University, Delhi, India
}

\begin{abstract}
Aircraft passengers and crew are lining a coronavirus disease pandemic. This pandemic may last for many months, stressing the aviation industries. With over two billion airline passengers yearly, in-flight transmission of contagious diseases is an essential worldwide health interest. Some attitudes of in-flight transmission have been registered, cases of coronavirus disease (COVID-19) have been reported in all over the world, traveling raises your risks of receiving and scattering COVID-19. Because of how air flows and is cleaned on airplanes, maximum viruses and other microorganisms do not spread effortlessly on flights. Nevertheless, there may be a possibility of receiving COVID-19 on crowded flights if there are other passengers inside the aircraft cabin with COVID-19. So the main objective of this study is to explain the relation between the aircraft cabin ventilation systems with the spread of COVID-19 inside an aircraft cabin. Aircraft ventilation strategies and their effect on air quality were discussed in this study. Control measures and some aircraft cabin seats arrangement proposals were also presented in this study.
\end{abstract}

Keywords- COVID-19, aircraft ventilation system, airborne disease, aircraft cabin.

\section{INTRODUCTION}

The impact of air travel on the expansion of infectious diseases has led to significant fear but limited study (Mangili et al 2005; Vogt TM ,2006). There is a stat which says that about 1 billion people travel in airplanes per year. In reality, more travelers are likely to be scared of any type of microbe diseases which is infectious in nature on their journey. There are many important ways in which air travel can be affected the worldwide expansion of new pop up and pre-existing infectious disease. Transmissibility may be expanded on the aircraft via close contact; airborne expand itself through small-particle aerosols, as in the case of some acute respiratory syndrome (SARS). Our understanding of the spread of inhalation infections on aircraft is very imperfect. Key questions include how often dispersal can occur by contaminated surfaces, large droplet spread, and airborne spread of small-particle aerosols, as well as the risk for specific organisms. The scientific uncertainty limits the capability to produce any preventive measures. Many types of commercial aircraft use vertical airflow and high-efficiency particulate air (HEPA) filters that should limit the exposure to small airborne droplets. However, there are no regulations requiring HEPA filters or for testing of the function of filters. (Ozonoff D, 2005) 
The COVID-19 pandemic presents specific dangers that encounter airline travelers. Travelling contains more than a few individual connections and sitting close to others for long times, both in flight and at airport entrances. These activities can raise the accidental contact to transmissible illnesses. This review explained the relation between the aircraft cabin ventilation systems with the extent of COVID-19 inside an aircraft cabin. Aircraft ventilation approaches and their effect on air quality were discussed in this study. Control measures and some aircraft cabin seats arrangement proposals are also presented in this study.

\section{PURPOSE}

The main Purpose of this study is to explain the relation between the aircraft cabin ventilation systems with the spread of COVID-19 inside an aircraft cabin. Aircraft ventilation strategies and their effect on air quality were discussed in this study. Control measures and some aircraft cabin seats arrangement proposals were also presented in this study.l

\section{LITERATURE REVIEW}

On 12 January 2020, the World Health Organization (WHO) confirmed that a novel coronavirus was the cause of a respiratory illness in a cluster of people in Wuhan City, Hubei Province, China, which was reported to the WHO on 31 December 2019 ( Reynolds Matt,2020). The case fatality ratio for COVID-19 has been much lower than SARS of 2003 (GOV.UK report,2020) but the transmission has been considerably greater, with a significant total death toll (WASAHQ Report , 2020) . COVID-19 is mainly initiated by contact or droplet transmission attributed to relatively large respiratory particles which are matter to gravitational forces and travel only approximately one meter from the patient. Airborne transmission may occur if patient respiratory activity or medical procedures generate respiratory aerosols. These aerosols contain particles that may float much longer distances and remain airborne longer, but their infective power is uncertain. Aircraft passengers and crew are confronting a coronavirus disease pandemic. This pandemic may last for many months, stressing the aviation industries.

Keeping Aircraft passengers and crew safe, healthy, and available to travel throughout this pandemic is critical. The consistent use of appropriate personal protective equipment (PPE) will help the assurance of its availability and Aircraft passenger's protection (Livingston E, Desai A \& Berkwits M.,2020) Aircraft passengers and crew are at risk of contagion during the severe acute respiratory syndrome coronavirus-2 pandemic. International guidance suggests direct droplet transmission is likely and airborne transmission occurs only with aerosol-generating procedures (Wilson NM, Norton A, Young FP \& Collins DW, 2020). Aircraft passengers and crew should appraise the current evidence regarding spread and apply this to the contagion occurrence. Measures to soften airborne transmission should be employed at times of risk.
However, the mechanisms

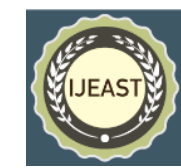
transmission are largely unconfirmed. Whilst awaiting robust evidence, a precautionary approach should be considered to assure Aircraft passengers and crew safety.

1- Aircraft cabin environment

Commercial airplanes voyage at a typical altitude of 11,000 meter where the outside temperature is about $-55{ }^{\circ} \mathrm{C}$, the atmospheric pressure is only about one-fifth of that at the sea level and the relative humidity is near zero. Under such a risky ambient environment, human beings cannot survive without being protected by an environmental control system (ECS) ( Elmaghraby, H.A., Y.W. Chiang, and A.A. Aliabadi , 2018 ; Barnes, N.M., et al 2018) . As a part of the ECS, air distribution system plays roles including distributing air suitably, cleaning up filthy air, and diminishing cross disease infection, towards to creating relaxed, healthy and safe cabin surroundings for passengers and crews. However, the current widely-used mixing air distribution system promotes air mixing by supplying high momentum air at the ceiling level and exhausting contaminated air at the deck level. The widespread air mixing is anticipated to dilute cabin inside generated contaminants and thus may impose risks of infectious airborne disease transmission. The outbreaks of airborne communicable diseases, such as the severe acute respiratory syndrome (SARS) in 2003 and COVID-19 in 2019, confirm such risks are not imaginary but may come to realism ( Lidia Morawska, Junji Cao, 2020). In addition, many long criticisms about cabin air quality and thermal ease should also be put with significant attentions. To demonstrate how the ECS works, a volume of air will be followed as it flows continuously from outside the airplane into the airplane cabin and, finally, exits the airplane. Figure 1 is a schematic of the ECS components for the Boeing 767 airplane. The Boeing 767 is a modern generation airplane that uses 50\% filtered recirculated air and 50\% outside air (a typical of modern generation airplanes).

The air delivered to passengers and crew on commercial jet aircraft is naturally a blend of conditioned external (ambient) air that has been diverted to the cabin from the engine compressor stages, and air that is taken from the cabin, filtered, and recirculated. The first filter of recirculated air traps the largest particles. Then, on most modern aircraft, the air passes through high efficiency particular air (HEPA) filters before reentering the passenger cabin (Mangili A, Vindenes $\mathrm{T}$, Gendreau M., 2015). The most efficient HEPA filters capture 99.97\% of particles between 0.1 and 0.3 micrometer and $100 \%$ of the larger particles. In a count, the ultra-small contagion also gets captured by Brownian and electrostatic forces. The environmental control system is designed to minimize the introduction of harmful contaminants into the cabin and to control cabin pressure, ventilation, and temperature. Most commercial aircraft provide 10 to 15 air changes per hour of the passenger cabin depending upon the aircraft type, as the original cabin air is diluted with incoming ambient air. Cabin 
airflow is mainly side to side and compartmentalized into four to seven seat rows within the passenger cabin, thereby limiting longitudinal (front to back and vice versa) cabin contamination. However, although the principle is side-to-side airflow, evidence employing computational fluid dynamic modeling in a mockup full-sized aircraft cabin section suggests that airflow patterns can be influenced by many factors including seat and cabin geometry, occupancy density, and thermal loads of passengers and equipment. Individual risk of infection of
COVID-19

within the many factors, including chance, source strength (generation rate of infectious agent), exposure (proximity to the source and duration of the exposure), and cabin ventilation. Infections during flights can be spread not only by aerosols that remain airborne and can be inhaled, but also by large droplets that settle on surfaces or by direct contact with secretion, body fluids, or contaminated surfaces.

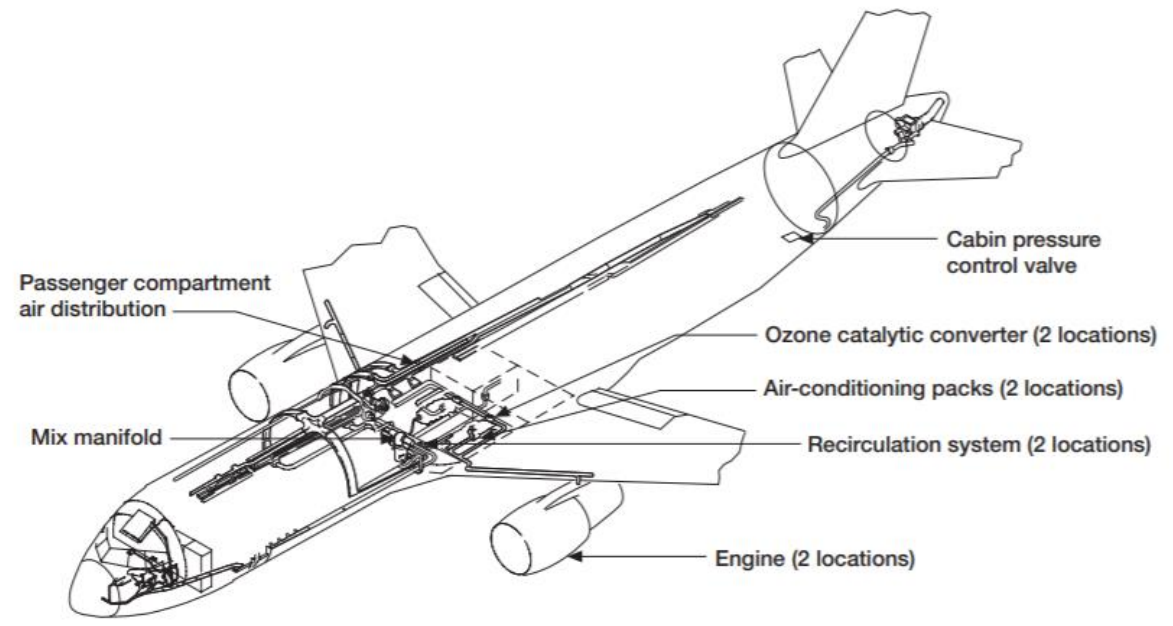

Figure 1: System layout for the Boeing 767 ECS (Hunt, E.H., et al,1995)

\section{2- Aircraft ventilation strategies and their effect on air quality and COVID-19 infection aboard}

Different ventilation plans have been examined as measures to control infection transmitted via airborne route and other gaseous and particulate contaminants commonly found in the aircraft cabin envelop. For aircraft cabins, ventilation effectiveness is defined as the portion of the outside fresh air supplied to the cabin that reaches the breathing zone of the occupants. Major studies that examined the effect of one or more ventilation system, such as mixing, displacement, and personalized ventilation, on air quality and disease spread aboard aircraft are discussed in different researches. Underaisle and underfloor ventilation systems are usually used as other names for the displacement ventilation system aboard aircraft. In such systems, air is supplied vertically from an under-floor plenum, usually located under the aisles, through perforated or nozzle vents. In aircraft cabins, personalized ventilation has been employed in various forms as a measure to protect the micro-environment of occupants from the invasion of contaminants and infectious organisms. (Wilson NM, Norton A, Young FP \& Collins DW ,2020)

Some researches confirmed that inlet and outlet should be near to each other to decrease airborne transmission but they did not explain the effect of inlet and outlet location on airflow distribution and thermal stability. To reduce airborne transmission, path transfer by air should be lowest and recirculation should be less. Credible scientific investigations of cabin air quality have been conducted by the National Academy of Sciences, United States Department of Transportation (DOT), National Institute for Occupational Safety and Health (NIOSH), Centers for Disease Control and Prevention (CDC), independent research groups, and airplane manufacturers (Wilson, N. M. Norton, A.Young, F. P.Collins, D. W,2020). Numerous engineers and researchers have worked on improving cabin air quality, thermal comfort, and air flow in recent years. As stated before, the ECSs function is to supply a given amount of fresh air at a certain pressure and temperature in order to maintain the cabin at such conditions that the comfort of passengers and crew is guaranteed. It is essential that ECSs in an aircraft be proficient of quickly heating up or cooling down cabins in order to deliver an acceptable thermal environment for passengers and crew members (Carlo Giaconia, Aldo Orioli, Alessandra Di Gangi, 2013 examined the temperature, pressure and humidity of an indoor air in aircraft. )

Some other studies have been published comparing displacement ventilation (DV) with other ventilation systems. The DV is an air distribution system which delivers cool fresh air with low velocity, generally at floor level and eliminates exhausted air at the ceiling. The temperature distribution is 
described by stratification: while cool, fresh and clean air can be found at floor level, the contaminated air rises up to the ceiling and is extracted there efficiently improving the air quality. (Zhu S., Srebic J ,2012 analyzed the performance of DV and Mixing Ventilation (MV) in different kinds of rooms). Computational Fluid Dynamics (CFD) models were used to compare DV and MV regarding airflow, temperature and comfort indices. DV turned out to provide a comparable or even better comfort level than MV, except for the space in the vicinity of floor diffusers or major heat sources. ( T Zhang*, Q Chen, 2005 Analyzed DV, MV and personalized ventilation in a section of a Boeing 767 cabin using CFD modelling). Temperature stratification was found in both systems but the vertical gradient was less than $3 \mathrm{~K}$. While in MV, high air velocities (and $\mathrm{CO} 2$ concentrations) were found, DV provided more comfort.

Several research work anxious compared DV, MV and PV(Personal Ventilation) with lateral provision in a mock-up based on different Airbus designs (Tengfei Zhang, Qingyan (Yan) Chen ,2007) . Air flow and temperature measurements were made as well as experiments with test persons and CFD simulations. The vertical temperature difference in DV and in MV with lateral support was in line with the standards for a volumetric flow rate of $77.8 \mathrm{l} / \mathrm{s} / \mathrm{cabin}$ and low air velocities were measured $(<0.2 \mathrm{~m} / \mathrm{s}$ ) ( Julia Maier, Claudia MarggrafMicheel, Tobias Dehne, Johannes Bosbach, 2017). An investigation conducted by the Committee on Airliner Cabin Air Quality in 1986 showed that the relative humidity (RH) decreases from $23 \%$ to $2 \%$ under regular cabin ventilation rates (Long Chen, Xingjuan Zhang, Chao Wang, Chunxin Yang ,2017). Low RH in the aircraft cabin may cause a number of problems, such as skin dryness, eye irritation, increased static electricity, and increases the survival time of virus such as SARS-CoV-2, influenza and SARS-CoV-1 viruses.

During and after the COVID-19 pandemic, researchers should study a new ventilation system with personalized air supply suitable to build a mini-environment in the commercial aircraft cabin. A personalized air distribution system provides clean air straight to the respiration area of somebody. The system generates a desirable micro-environment with fresh air. The personalized air distribution system may deliver a decent air quality, but the danger could be even higher than the displacement ventilation system. Researchers should study a suitable seat arrangement, which may decrease the risk of infectious diseases like COVID-19. Hence in this study we proposed some seat arrangement concepts which will need experimental and CFD simulation analysis before concluding the suitable seat arrangement in a commercial aircraft cabin.

\section{3- Control measures}

A key constituent of infection control, particularly for diseases with airborne spread has been reported. For example, the COVID-19 outburst involved passengers to seat as far as two rows from the index passenger. Multiple mathematical models of probability of infection

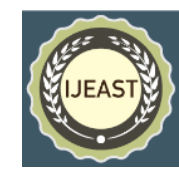
perhaps the most commonly used is the Wells Riley calculation, which has been used to study both tuberculosis and measles outbreaks (Noakes CJ, Sleigh PA.,2009) Correct ventilation within any confined space decreases the concentration of airborne organisms in a logarithmic fashion. In the case of recirculated systems, such as on recent aircraft, where several sections of air from the cabin are recirculated and mixed with fresh air, this relationship holds only if the recirculated air experiences filtration through HEPA filters. Although the practice of removing transmissible airborne particles from recirculated air through HEPA filtering is well accepted as an impressive transmission control measure, the use of HEPA filters within commercial aircraft is neither required nor regulated by the Federal Aviation Administration or its British (Civil Aviation Authority) and European (Joint Aviation Authority) counterparts (Mangili A, Vindenes T, Gendreau M.,2015)

A 2004 survey of major U.S. commercial air carriers by the U.S. Government Accountability Office found that $15 \%$ of large commercial aircraft within the U.S. domestic fleet did not routinely use HEPA air filtering and that nearly $50 \%$ of smaller regional commercial aircraft did not (David Schlossberg, 2016). Incorporating epidemiological data into risk assessment mathematical models may provide insight into how proximity and ventilation influence disease transmission aboard commercial aircraft. A major public health situation is created by the expectation of travel from one country to another within one day, a period of time which is little than the incubation time period. This allows for most passengers infected with COVID-19 to pass through entry screening undetected and reach their destination before they become symptomatic. Although many countries practice entry screening, studies reveal that this is very ineffective. Khan et al.'s retrospective evaluation of entry and exit screening of airline travelers during the 2009-2010 H1N1 pandemic states that entry screening is an anachronism and says interventions to mitigate the international spread of infectious disease whether through alertness or response would have the greatest global impact if implemented as close as possible to the sources of any future epidemic threats (i.e., exit screening).( Khan K, Eckhardt R, Brownstein JS, Naqvi R, Hu W, Kossowsky D, Scales D, Arino J, MacDonald M, Wang J, Sears J \&Cetron MS, 2013)

\section{4- Two rows arrangement}

Any passenger flight from any country infected by the COVID19, who was seated within two rows of a passenger diagnosed with COVID-19 shortly after they had taken a flight from one region to another should also be quarantined for fourteen days. But the statement led some to wonder why only those seated within two rows of the passenger; the answer is "That is close contact within the context of a plane." This approach is based on guidance from the World Health Organization (WHO), which defines "close contact" as being within one meter of an infectious passenger. Outside the situation of a plane, close 
contact is defined as "face-to-face contact" or "spending more than 15 minutes within two meters of an infected person.

This review devised a "seating heat map", to show the chance of every traveler on a flight becoming infected by somebody with COVID-19 who is seated in an aisle seat in the middle of the plane. The imaginary infectious passenger is seated at the red seat. Passengers seated within a one meter radius of the putative patient were at highest risk (yellow seats), followed by passenger seated within more than one meter radius(Blue seats) were at low risk, followed by a crew passing in front of the putative patient was at high risk, another crew member was passing within more than one meter radius in front the sick passenger was at medium

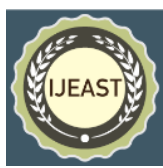
crew member was passing within more than one meter radius behind the sick passenger was a low risk. Public health bodies making contact with passenger's seated two rows in either direction should, in normal circumstances, be more than careful enough. This review mapped the behavior of passengers seated in economy class on a Boeing 767 cabin. Our study advises that the aisle seats is the riskiest place to sit, even someone in an aisle seat just two rows in front of an infected passenger would have bit to worry about. It is not known yet precisely how this novel of coronavirus (COVID-19) is spread.
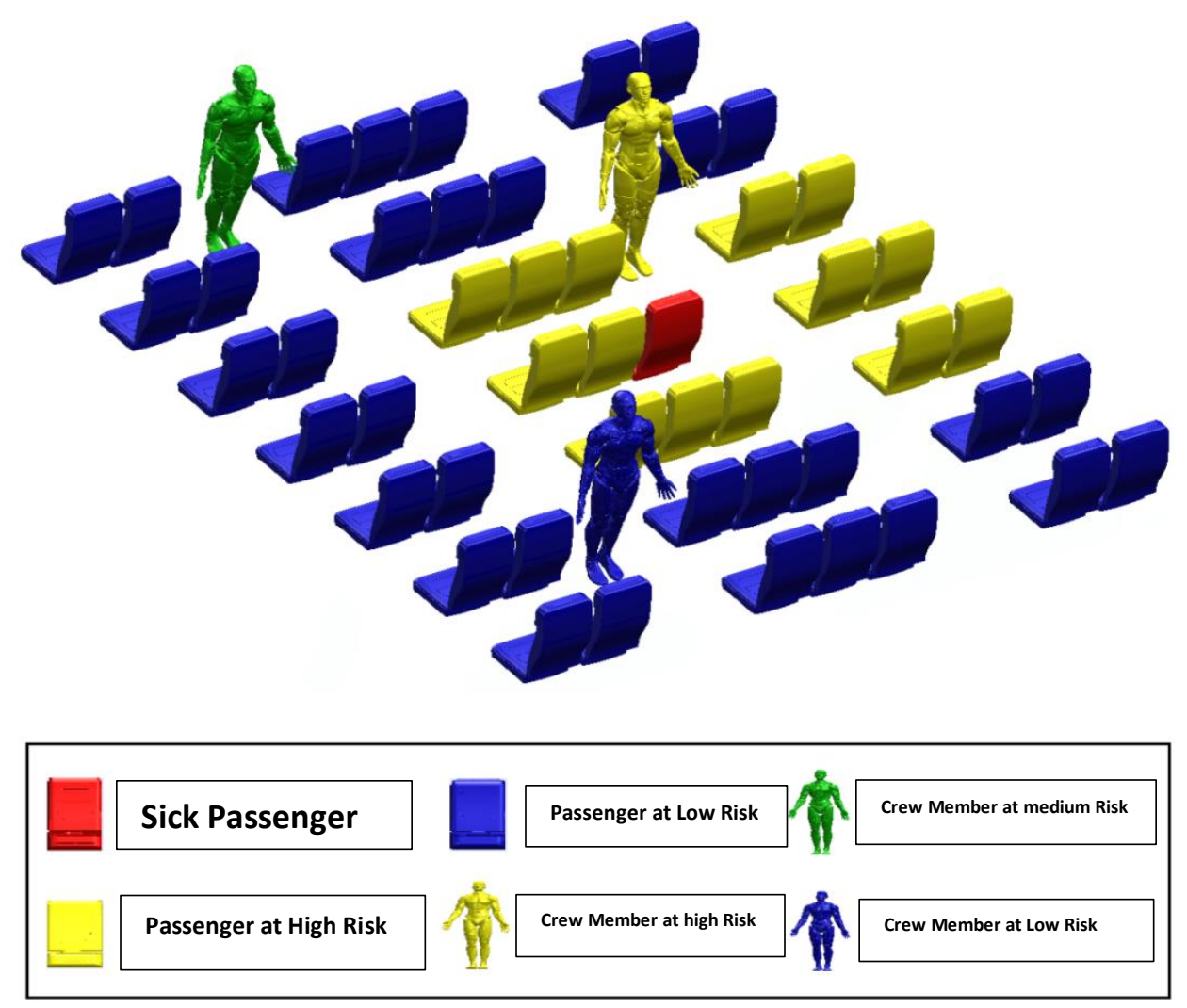

Figure 2: The 2-row infection zone diagram

\section{5- Seat arrangement Proposals for preventing the Spread of COVID-19 in aircraft cabins}

The passenger seat arrangement for the aircraft has been the same since years of aviation flights. Due to the beginning of various diseases and their spread in the aircraft cabin, it is of interest for the researcher to try to investigate different seat arrangement, which may contribute in decrease level of infection for the passengers (due to the sick passenger). Therefore, the following three arrangements of seats are proposed, that may be numerically simulated for the investigation of infection risk.

Firstly, we designed a concept that features forward-facing window and aisle seats with rear-facing middle seats as can be seen in figure 3 . The middle seats are flanked by a wraparound clear shield that separates them from their two neighboring seats. This is just one of many designs we have seen in the wake of COVID-19 as the travel industry prepares for a more cautious approach as things start up again. This concept is renowned by the opposite position of the middle chair of the triple to guarantee the extreme separation between travelers 
seated next to each other. Even though traveler seated on the side chairs, aisle and fuselage, stay to be positioned in the flight direction as normal, the passenger sitting in the middle is facing backwards. In fact this arrangement permits all three travelers to be parted with a protection made of translucent material that separates them from each other, making a shielding barrier from each person; each traveler has its personal space quarantined from others.

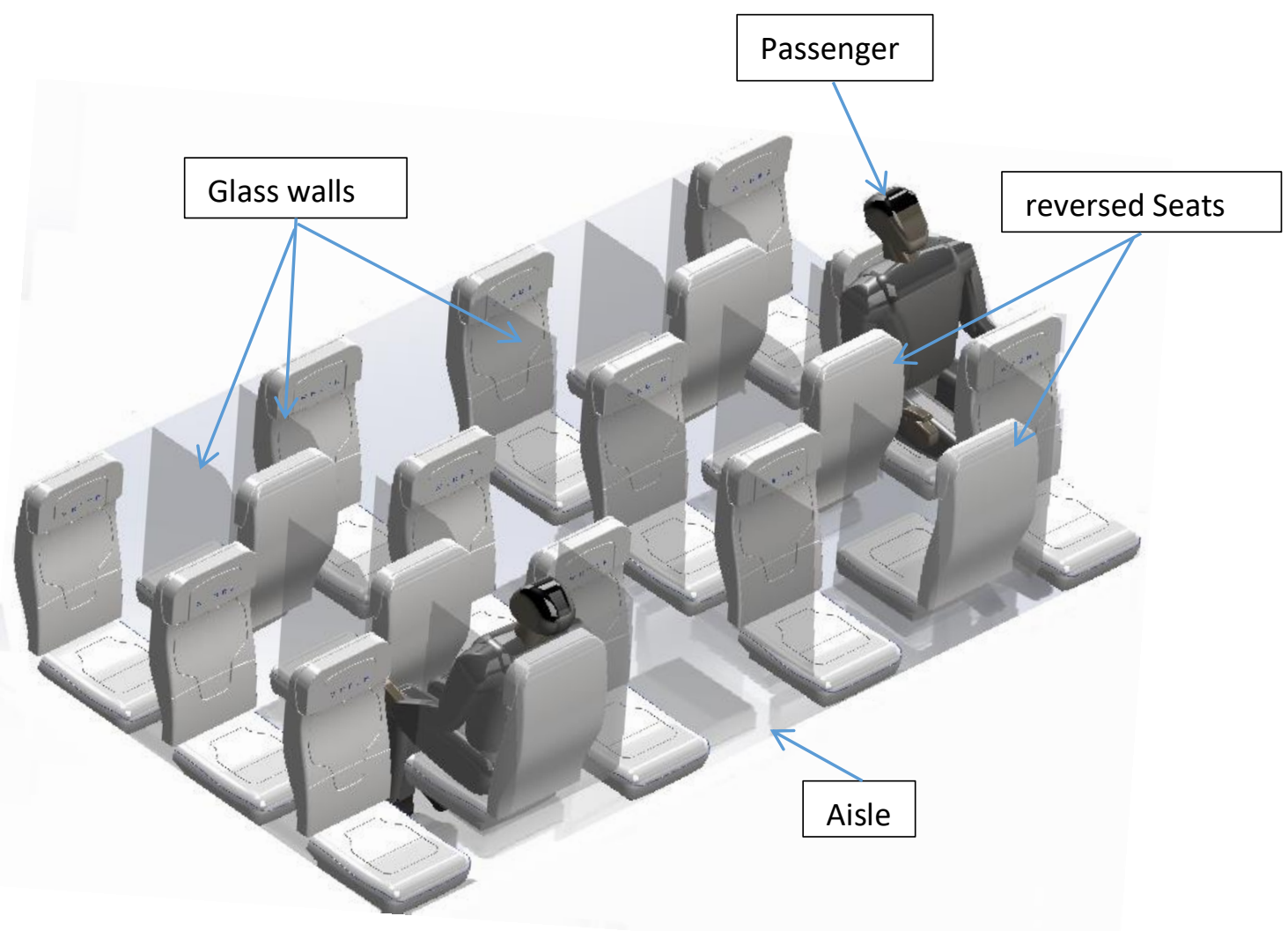

Figure 3 : Forward-facing window and aisle seats with rear-facing middle seats Concept

Secondly, we designed a seat arrangement concepts, which we use the Boeing 737 cabin seat arrangement modification as can be seen in figure 4, which the second seat arrangement concept, it is assumed that after the take-off the seats are rotated 90 degrees (towards the window).
Each of the rows is again divided with a partition wall. There are personal vents for each passenger (from the top), along with the Longitudinal Inlet present in the top. There are also longitudinal Outlets present on each side of the cabin. 


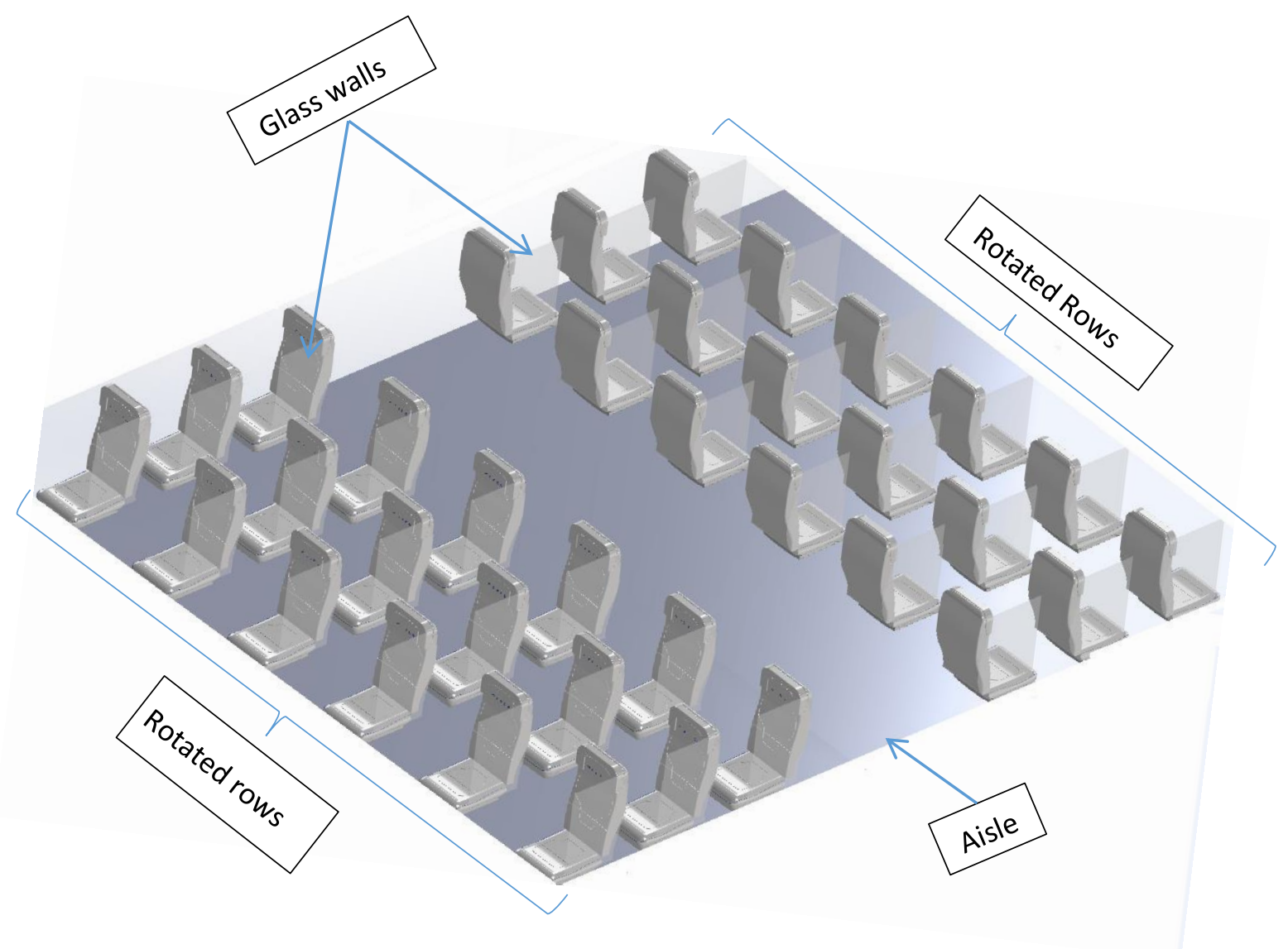

Figure 4 : The rotation of rows arrangement concept

Finally, we designed a third seat arrangement concept, it is assumed that after the take-off the seats are rotated 90 degrees in the pattern seen in figure 5. The middle row is with a partition wall, for preventing them to be in the direct vicinity of the second column passenger. There are personal vents for each passenger (from the top), along with the Longitudinal Inlet present in the top. There are two longitudinal Outlets present on each side of the cabin along with the horizontal outlets present after each row. 


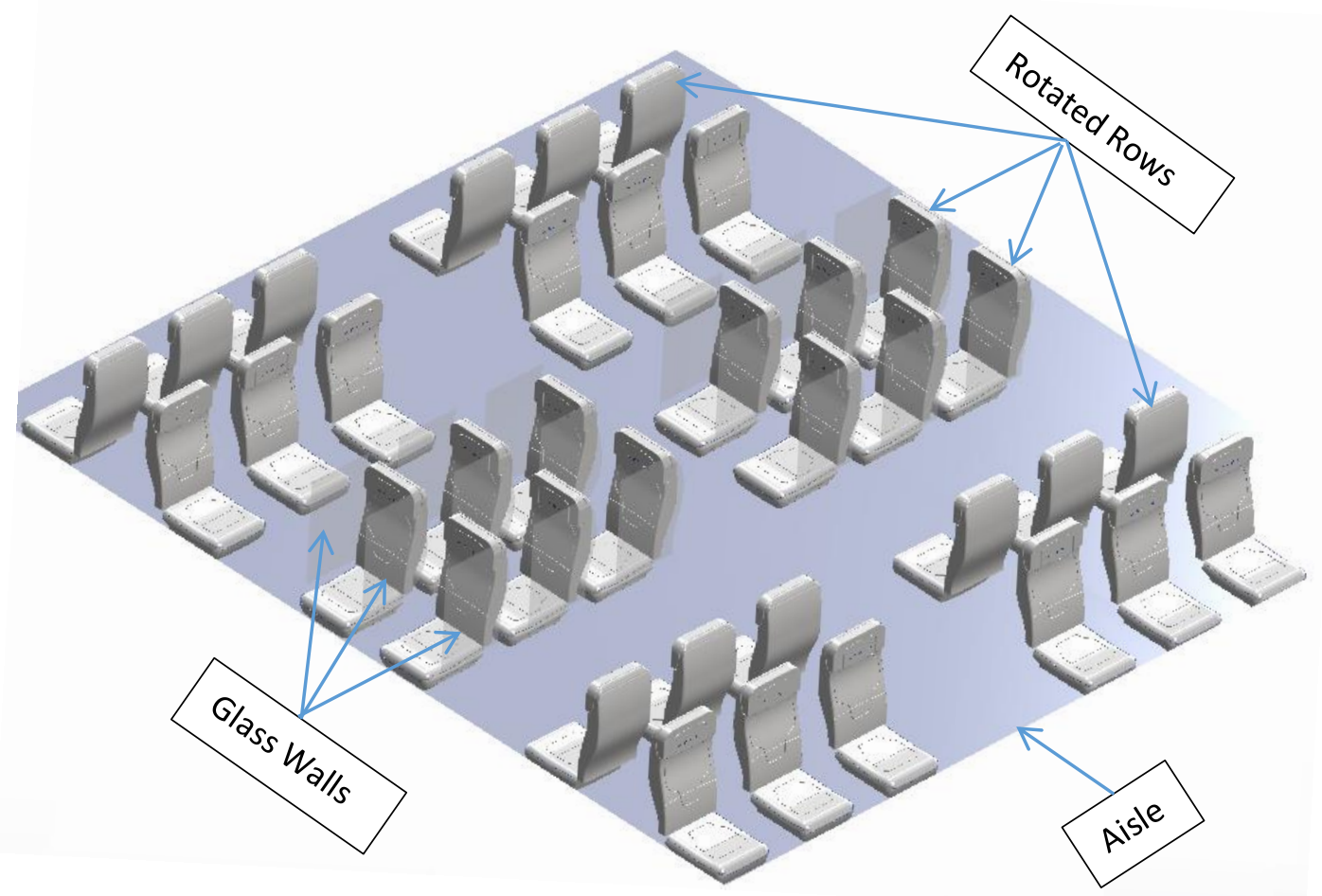

Figure 5 : Multiple rotations of seats arrangement concept

\section{METHODOLOGY}

The authors are all contributed for this review. After doing some researches about the risk infection of COVID-19 in an enclosed room or enclosed space, the authors decided to explain the infection risk of COVID-19 inside an aircraft cabin. We came out with some control measures for the decrease of the infection risk of COVID-19 inside an aircraft cabin. As we know that the passenger seat arrangement for the aircraft has been the same since years of aviation flights and due to the beginning of COVID-19 and its spread in the aircraft cabin, it is of interest for the researcher to try to investigate different seat arrangement, which may contribute in decrease level of infection for the passengers (due to the sick passenger). Therefore, the authors proposed three arrangements of seats that may be numerically simulated for the investigation of infection risk. The authors used Solidworks Software to Build the seat arrangements.

\section{CONCLUSIONS}

The way to destroy almost any risk of infection in an aircraft cabin and to prevent the aircraft from serving as a transport for international epidemic spreading is to stop travelers from traveling if they either have been exposed considerably to a contagious disease like COVID-19. Prevention is the most essential way of control and requires an active movement. For aircraft passengers, practicing hand hygiene and wearing surgical masks remains the most efficient way of decreasing probability of transmission. Developed international regulations respecting the examination, authorization, and reparation of aircraft environmental control systems are secured. Regulations necessitate HEPA filters for any aircraft using recirculated air are needed to decrease the probability of infectious spread on and by commercial aircraft. Due to the beginning of COVID-19 and its spread in the aircraft cabin, it is of interest for the researcher to try to investigate different seat arrangement, which may contribute in decrease level of infection for the passengers. Our research advises that the aisle seats is the riskiest place to sit, even someone in an aisle seat 


\section{International Journal of Engineering Applied Sciences and Technology, 2020}

Vol. 5, Issue 3, ISSN No. 2455-2143, Pages 661-670

Published Online July 2020 in IJEAST (http://www.ijeast.com)

just two rows in front of an infected passenger would have bitty to worry about. Aviation industries should study a novel personal ventilation suitable to build a mini-environment inside a commercial aircraft cabin.

\section{RECOMMENDATIONS}

1. Aviation industries should study a novel personal ventilation suitable to build a mini-environment inside a commercial aircraft cabin

2. A novel seat arrangement may also be studied for future aircraft cabins.

\section{ACKNOWLEDGEMENTS}

Authors would like to thank their Professors and colleagues for their guides and supports. Especially Mr. Raj Kumar Singh of Delhi Technological University to support through out the research work \& suggesting some good techniques.

\section{REFERENCES}

[1] Elsevier. "Novel Coronavirus Information Center". Elsevier Connect. Archived from the original on 30 January 2020. Retrieved 15 March 2020.

[2] Reynolds, Matt (4 March 2020). "What is coronavirus and how close is it to becoming a pandemic?". Wired UK. ISSN 1357-0978. Archived from the original on 5 March 2020. Retrieved 5 March 2020.

[3] Crunching the numbers for coronavirus". Imperial News. Archived from the original on 19 March 2020. Retrieved 15 March 2020

[4] "High consequence infectious diseases (HCID); Guidance and information about high consequence infectious diseases and their management in England". GOV.UK. Archivedfrom the original on 3 March 2020. Retrieved 17 March 2020.

[5] "World Federation Of Societies of Anaesthesiologists Coronavirus". www.wfsahq.org. Archived from the original on 12 March 2020. Retrieved 15 March 2020.

[6] Livingston E, Desai A, Berkwits M. Sourcing Personal Protective Equipment During the COVID-19 Pandemic. JAMA. 2020 Mar 28. doi: 10.1001/jama.2020.5317. Epub ahead of print. PMID: 32221579.

[7] Wilson NM, Norton A, Young FP, Collins DW. Airborne transmission of severe acute respiratory syndrome coronavirus2 to healthcare workers: a narrative review. Anaesthesia. 2020 Apr 20:10.1111/anae.15093. doi: 10.1111/anae.15093.

[8] Elmaghraby, H.A., Y.W. Chiang, and A.A. Aliabadi, Ventilation strategies and air quality management in passenger aircraft cabins: A review of

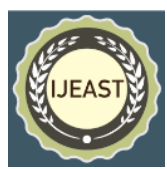
approaches and numerical simulations. Science and Technology for the Built Environment, 2018. 24(2): p. 160-175.

[9] Barnes, N.M., et al., In-Cabin Air Quality during Driving and Engine Idling in Air-Conditioned Private Vehicles in Hong Kong. International Journal of Environmental Research and Public Health, 2018. 15(4).

[10] Lidia Morawska, Junji Cao, Airborne transmission of SARS-CoV-2: The world should face the reality, Environment International, Volume 139, 2020, 105730, ISSN 0160-4120, doi.org/10.1016/j.envint.2020.105730.

[11] Mangili A, Vindenes T, Gendreau M. Infectious Risks of Air Travel. Microbiol Spectr. 2015 Oct;3(5). doi: 10.1128/microbiolspec.IOL5-0009-2015. PMID: 26542037.

[12] Hunt, E.H., et al., Commercial airliner environmental control system - Engineering aspects of cabin air quality. Aerospace Medical Association Annual Meeting, 1995: p. 1-8.

[13] Wilson NM, Norton A, Young FP, Collins DW. Airborne transmission of severe acute respiratory syndrome coronavirus2 to healthcare workers: a narrative review. Anaesthesia. 2020 Apr 20:10.1111/anae.15093. doi: 10.1111/anae.15093. Epub ahead of print. PMID: 32311771; PMCID: PMC7264768.

[14] Wilson, N. M. Norton, A.Young, F. P.Collins, D. W."Airborne transmission of severe acute respiratory syndrome coronavirus-2 to healthcare workers: a narrative review" 2020 ;doi.10.1111/anae.15093,PMC7264768

Anaesthesia-

[15] Carlo Giaconia, Aldo Orioli, Alessandra Di Gangi,Air quality and relative humidity in commercial aircrafts: An experimental investigation on short-haul domestic flights, Building and Environment, Volume 67,2013, Pages 6981,ISSN 0360-1323,doi.org/10.1016/j.buildenv.2013.05.006.

[16] Zhu S., Srebic J., et all, An advanced numerical model for the assessment of airborne transmission of influenza in bus microenvironments, Building and Environment 47, pp. 67-75, 2012

[17] T Zhang*, Q Chen. Comparison of different ventilation systems for commercial. Aircraft cabins. Indoor Air 2005. 3205.

[18] Tengfei Zhang, Qingyan (Yan) Chen,Novel air distribution systems for commercial aircraft cabins, Building and Environment, Volume 42, Issue 4,2007,Pages 1675-1684,ISSN 0360-1323, doi.org/10.1016/j.buildenv.2006.02.014. 
[19] Julia Maier, Claudia Marggraf-Micheel, Tobias Dehne, Johannes Bosbach,Thermal comfort of different displacement ventilation systems in an aircraft passenger cabin,Building and Environment,Volume111,2017,Pages256-264,ISSN0360-

1323, doi.org/10.1016/j.buildenv.2016.11.017.

[20] Long Chen, Xingjuan Zhang, Chao Wang, Chunxin Yang, A novel environmental control system facilitating humidification for commercial aircraft,Building and Environment,Volume126,2017,Pages34-41,ISSN0360-1323, doi.org/10.1016/j.buildenv.2017.09.013.

[21] Noakes CJ, Sleigh PA. Mathematical models for assessing the role of airflow on the risk of airborne infection in hospital wards. J R Soc Interface.

2009 Dec 6;6 Suppl 6(Suppl 6):S791-800. doi:10.1098/rsif.2009.0305.focus.

[22] Mangili A, Vindenes T, Gendreau M. Infectious Risks of Air Travel. Microbiol Spectr. 2015 Oct;3(5). doi:10.1128/microbiolspec.IOL5-0009-2015.

[23] David Schlossberg ,"Infections of Leisure" Fifth Edition2016, eISBN : 9781555819231 , doi:10.1128/9781555819231

[24] Khan K, Eckhardt R, Brownstein JS, Naqvi R, Hu W, Kossowsky D, Scales D, Arino J, MacDonald M, Wang J, Sears J, Cetron MS. Entry and exit screening of airline travellers during the $\mathrm{A}(\mathrm{H} 1 \mathrm{~N} 1) 2009$ pandemic: a retrospective evaluation. Bull World Health Organ. 2013 May 1;91(5):368-76. doi: 10.2471/BLT.12.114777. 